\title{
Hydrological modeling of floods in the Wadi Bechar watershed and evaluation of the climate impact in arid zones (southwest of Algeria)
}

\author{
Abdelghani Bekhira ${ }^{1} \cdot$ Mohammed Habi ${ }^{1} \cdot$ Boutkhil Morsli ${ }^{2}$
}

Received: 17 January 2018 / Accepted: 19 September 2018 / Published online: 27 September 2018

(c) The Author(s) 2018

\begin{abstract}
Precise knowledge regarding the quantities of water available in the Wadi Bechar watershed and better management of this resource is necessary to initiate the transformation of rainfall data into hydrometric data (simulated flow); this is the main objective of the hydrological rainfall-runoff modeling. The primary focus of this paper is the rainfall-runoff modeling on an annual and monthly scale in the Wadi Bechar watershed which covers an area of $6858 \mathrm{~km}^{2}$. We employ the rural engineering model (GR) for annual timestep GR1A and for the monthly timestep GR2M. The input parameters are precipitation $(P)$ and evapotranspiration (ETP) calculated by the Turc method; the output parameter is elapsed water slide $(Q)$. The results obtained indicate that the model takes into account the different atmospheric and underground exchanges, as well as the capacities of the production tank and routing tank. With this work, the contribution of precipitation to flows downstream of the watershed can be evaluated and quantified. On an annual scale, the potential evapotranspiration modulator coefficient $X$ is equal to $2.20>1$. This indicates that the water from the Wadi Bechar watershed seeps into the ground or into the adjacent watersheds of Wadi Zousfana and Wadi Guir. On a monthly scale, we calibrate and cross-validate the model with the selected input data, determining the model parameter sets that best reflect the transformation of rainfall into flow. The calibration was done with several passages in computer. The value of the capacity of the estimated production tank $X 1$ is equal to $4.74 \mathrm{~mm}$, which reflects the production function, and subsequently indicates the rainfall capacity transformed into a water flow available for runoff at the Wadi Bechar watershed scale. The value of the estimated underground exchange coefficient parameter $X 2$ is equal to 0.02 ; it reflects the transfer function, which indicates the movement of this surface flow toward the watershed outlet.
\end{abstract}

Keywords Precipitation · Hydrological modeling (GR1A and GR2M) · Arid zone · Wadi Bechar watershed

\section{Introduction}

Knowledge of a watershed is very important because it is the general framework and fundamental unit of hydrological studies and can provide insight into natural hazards or

Abdelghani Bekhira

hydraubakh@yahoo.fr

Mohammed Habi

moha.habi@gmx.de

Boutkhil Morsli

morbinrf@yahoo.fr

1 Laboratory 60 "Water Resources Development”, University of Tlemcen, BP 230, 13000 Tlemcen, Algeria

2 National Institute for Forest Research (NIFR), BP 88, 13000 Mansourah, Tlemcen, Algeria into the vulnerability of water resources. The problems highlighted today in arid zones are that water resources are poorly exploited and poorly known by those responsible. Unfortunately, in recent years, our region has had difficulties in ensuring proper hydrological monitoring of the Wadi Bechar watershed (Bekhira et al. 2014) and its tributaries due to the reduction in the number of meteorological stations. (There exists only one rainfall station and one active hydrometric station) Occasionally, due to a lack of human and financial resources, these stations are considered unimportant. In particular, in our region, data pertaining to water resources and their seasonal variations displays weaknesses with distorted hydrological data sets (ANRH 2014). The available flow periods for a reliable hydrological analysis are often incomplete, discontinuous, short-lived, and consequently difficult to exploit, and it is in the interest of hydrological models to overcome these problems (Bodian 
et al. 2012, 2015). The absence of adequate information on the Wadi Bechar watershed is a major handicap both for researchers in this field and for its development. The highlighted problem in the arid zones is also a rarity of hydrological models because the rainfall series are available but with fewer gaps (Bodian et al. 2015; Bouanani et al. 2015; Hughes 2009; Pilgrim et al. 2009). The rainfall-runoff relationship modeling is one of the solutions to this lack of data (Bodian et al. 2012). This is the reason to be interested in rainfall-runoff models that helps reconstitute or complete the flow series of a watercourse from the existing rainfall series using the GR (Rural Engineering) model from Cemagref (GR1A for an annual timestep, GR2M for a monthly timestep, and GR4J for a daily timestep) (Nash and Sutcliffe 1970) which is characterized by simplicity of use, adaptability, and robustness (Bouanani et al. 2015). The GR models have been tested on a wide variety of basins and climatic contexts (Mouelhi et al. 2013; Rwasoka et al. 2013; Traore et al. 2014; Bouanani et al. 2015; Kouakou et al. 2016; Lyon et al. 2017; Niemi et al. 2017; Otmane et al. 2017; Nounangnonhou et al. 2018). They have been tested on watersheds ranging from less than $10 \mathrm{~km}^{2}$ to more than $100,000 \mathrm{~km}^{2}$. They are also used for a wide range of operational applications such as flood predetermination, flood and low-water flows forecasting, impact detection, management, or dimensioning of structures (Bouanani et al. 2015).

We will use here the GR1A conceptual model (Rural Engineering for an annual timestep with one parameter) and GR2M (rural engineering for a monthly timestep with two parameters) (Mouelhi 2003; Mouelhi et al. 2006).

The simulation of the flow at the outlet of a watershed is necessary and essential for many applications of engineering and water resource management, such as sizing and management of structures, flood forecasting, impact detection, among others (Bouanani et al. 2015).

The objective of this paper is to find the optimal parameters of each model GR1A and GR2M and ascertain which model allows a better simulation in order to appreciate the simulated flows for the prediction, then to evaluate the watershed of the Wadi Bechar in a way to estimate the productivity at the production tank and the storage at the routing tank according to the climatic parameters, as well as to evaluate the evolution of the hydrological balance parameters of the Wadi Bechar watershed in the context of climate change.

The results obtained from this modeling will allow us to validate this model in the arid zones of annual timestep GR1A and on monthly time GR2M. On the one hand, our share of quantities and evaluations of the climatic impact on the duration of events is also a factor influencing the flow. The studies conducted in West Africa have shown that climate variability and change have a strong impact on hydro systems (Kouakou et al. 2016).
The results obtained show that the Wadi Bechar watershed is not productive because evaporation is very high and rainfall is rare. Moreover, the possibility of storage is important. The watershed loss of water from the adjacent basin shows that there is significant infiltration due to the geological formation and hydrology of the Bechar region. According to Mekideche et al. (1995), the region of Bechar is characterized by the aquifers of the limestones of Turonian which contains cracked limestones.

\section{Materials and methods}

\section{Study area}

The Wadi Bechar watershed is located in the southwest of Algeria (Fig. 1), between $0.70^{\circ} \mathrm{W}$ and $0.37^{\circ} \mathrm{W}$ meridians. The climate of Bechar is monitored by a weather station located in longitude $31^{\circ} 37^{\prime} 00^{\prime \prime} \mathrm{N}$ and in latitude $02^{\circ} 14^{\prime} 00^{\prime \prime} \mathrm{W}$ and with an altitude of $772 \mathrm{~m}$, indexed by 1301 32. The station is managed by the ANRH (National Agency for Hydraulic Resources). The length of Bechar watercourse is $140 \mathrm{~km}$, and it drains a vast watershed of $6858 \mathrm{~km}^{2}$. It is located at the foot of the southern slope of the Saharan Atlas, bound in the north by the Djebel Grouz mountain range, in the southwest by the Ougarta mountain range, in the southeast by the Great Western Erg, in the west by the Hamada of the Guir, and in the east by the Hamada of Namous watercourse. It takes its source at Djebel Grouz which has an altitude of $1590 \mathrm{~m}$. Numerous geological works have been devoted to the study of the Paleozoic of the Bechar region (Menchikoff 1936; Pareyn 1961; Deleau 1952), to which are added the results of research and exploitation work on solid and liquid fuels (coal and oil), carried out by foreign and national companies (Southern Oran's collieries, Algerian Mining Research Office (BRMA), National Society for Research and Exploitation of Petroleum in Algeria (SN REPAL), National Society for Research and Exploitation of Mining Resources (SONAREM), and National Society for Research, Production, Transport, Transformation, and Marketing of Hydrocarbons (SONATRACH)).

The Bechar region is part of the Saharan platform, which consists of the following.

The Saharan Atlas in the north, represented by the Jurassic mountains of Djebel Grouz, orientated EW; The Hamada of the Guir in the West, where outcrop the Pliocene lacustrines limestones (south) and the Quaternary formations (in the north); The Great Western Erg in the southeast and the Ougarta Lower Paleozoic chains in the south.

We can note tectonic structures (Zousfana watercourse anticlinorium, Chebkat Mennouna anticline) and numerous basins as well: 


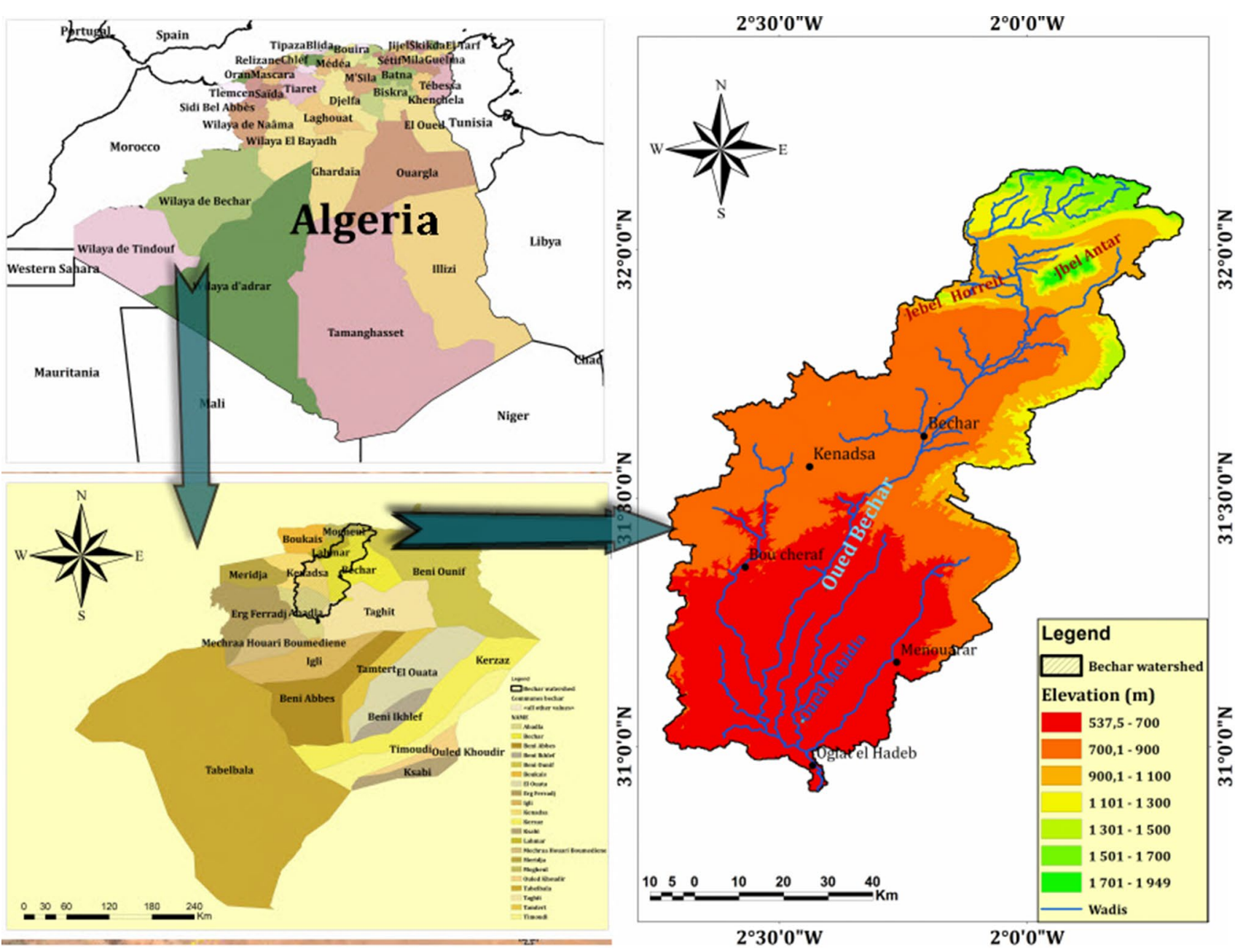

Fig. 1 Geographical location of the Wadi Bechar watershed (Bekhira et al. 2014)

- Cretaceous saline basin (northwest of Bechar).

- Coal basins (Westphalian-Stephanian).

Bechar-Kenadsa, Abadla-Ghorassa and Mézarif-Nekheila.

- The Chebkat Fendi Jurassic basin.

This area consists of various geological terrains, ranging from the Precambrian to the present.

It is split into two parts (Menchikoff 1936):

- The Southern part, belonging to the previous Saharan platform, lightly deformed at the Hercynian period.
- The northern part is part of the Atlas domain, deformed energetically at the Hercynian and violently recovered from the Alpine.

\section{Modeling rainfall-runoff relationship}

\section{The GR1A model}

The structure of the model is very simple since it is based on a simple equation: the flow $Q_{k}$ of year $k$ being proportional to the rainfall $P_{k}$ of the same year, with a flow coefficient dependent on $P_{k}$, rainfall $P_{k-1}$ of year $k-1$ and on the annual mean potential evapotranspiration $E$. The equation is written as 
$Q_{k}=P_{k}\left\{1-\frac{1}{\left[1+\left(\frac{0.7 P_{k}+0.3 P_{k-1}}{X . E}\right)^{2}\right]^{0.5}}\right\}$

where $X$ is the unique parameter of the model and $E$ is the annual mean potential evapotranspiration.

The model contains of only one optimizable parameter, dimensionless $X$ parameter, which appears as a modulating coefficient of potential evapotranspiration.

From a large watersheds sampling, the median of $X$ is 0.7 and a $90 \%$ confidence interval is given by $[0.13 ; 3.5]$ (Bouanani et al. 2015).

\section{The GR2M model}

This model was developed successively by Kabouya (1990), Kabouya and Michel (1991), Makhlouf and Michel (1994), Mouelhi (2003), and Mouelhi et al. (2006). The version presented here is that of Mouelhi et al. (2006).

Its structure associates a production reservoir with a routing tank and an opening to the outside. These three functions simulate the hydrological behavior of the basin. A diagram of the structure is shown in Fig. 2, where $P_{k}$ is the monthly rainfall of the month $k$ and $E$ is the mean potential evapotranspiration for the same calendar month

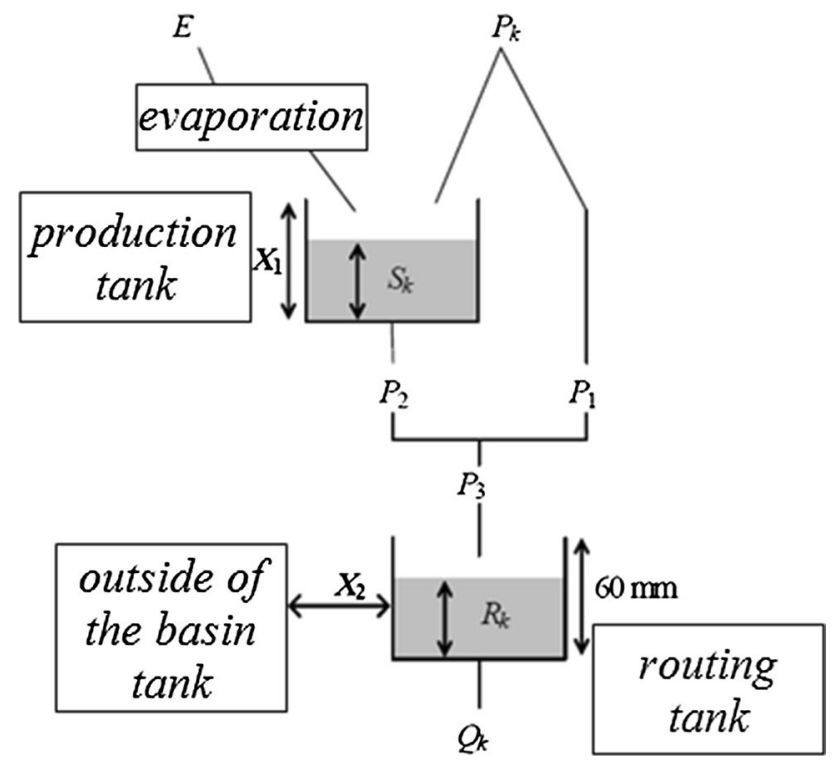

Fig. 2 Structure diagram of the GR2M model (Bouanani et al. 2015)
Table 1 GR2M model parameters value (Bouanani et al. 2015)

\begin{tabular}{lll}
\hline Parameter & Median & $\begin{array}{l}90 \% \\
\text { confidence } \\
\text { interval }\end{array}$ \\
\hline$X 1(\mathrm{~mm})$ & 380 & $140-2640$ \\
$X 2(-)$ & 0.92 & $0.21-1.31$ \\
\hline
\end{tabular}

(Bouanani et al. 2015). It contains two free parameters to set $X 1$ and $X 2 . X 1$ intervenes in the "production function" part, while $X 2$ intervenes in the "transfer function" part. The production function reflects the actual transformation of rainfall into a flow of water available for runoff; the transfer function is the result of the movement of this runoff accumulated on the ground during precipitation toward the watershed outlet.

From a large watershed sample, we obtain the data given in Table 1 (Bouanani et al. 2015).

\section{The model optimization}

The optimization (or calibration) of the model parameters requires the definition of a function quantifying the error of the model, that is to say the difference between the observed and the simulated flows. The quantitative criterion used to measure the quality of the model adjustments is that proposed by Nash and Sutcliffe (1970), called Nash in current hydrological usage, and is defined as follows

$\operatorname{Nash}(Q)=1-\frac{\sum_{i=1}^{n}\left(Q_{\mathrm{obs}, i}-Q_{\mathrm{cal}, i}\right)^{2}}{\sum_{i=1}^{n}\left(Q_{\mathrm{obs}, i}-\overline{Q_{\mathrm{obs}}}\right)^{2}}$

where $Q_{\mathrm{obs}, i}$ is the flow rate observed at the timestep $i, Q_{\mathrm{cal}, i}$ is the simulated flow at the timestep $i, Q_{\text {obs }}$ is the observed average flow rate, $N$ is the total number of timesteps of the simulation period.

Table 2 Values of the parameters after calibration and performance of the Wadi Bechar watershed

\begin{tabular}{lllll}
\hline Annual data & \multicolumn{4}{l}{ ETP (Turc) } \\
\cline { 2 - 5 } Criteria & $X$ & Nash $(\%)$ & Balance $(\%)$ & $\left(R^{2}\right)$ \\
\hline Wadi Bechar & 2.2 & 77.9 & 89.1 & 0.798 \\
\hline$X=$ ETP correction coefficient (mm) (potential evapotranspiration)
\end{tabular}

The Nash criterion evaluates the quality of the simulation results compared to the observations, both in terms of phase and intensity varying from $-\infty$ to 1 (Nash and Sutcliffe 1970). The adjusted model is all the more better as this function is close to 1 . A Nash criterion of less than 
0.60 value is an indication of a faulty model on the studied watershed (Kabouya and Michel 1991).

\section{Results and discussion}

\section{The GR model application}

\section{Annual model GR1A}

In this task, the observed annual rainfall values and the ETP calculated by the Turc's method and the annual flows (expressed in water surface flow for the 1985-2010 periods) are used at the entrance of the model. The calibration validation was made by applying the performance test of the coefficient of determination model $R^{2}$ (Table 2 ).

Initially, we run the model in calibration only over the whole of the above-mentioned period. We have made changes to the model parameter $X$ starting with the value 0.13 (minimal value given by the GR1A designer) and increasing it successively at an interval of 0.01 to the upper limit value 3.5 given by the model. We obtained the best calibration with the value of parameter $X$ equal to 2.2 (Table 2).

The curve of the elapsed surface water flow calculated and that measured indicate almost perfect superposition for the Wadi Bechar watershed (Fig. 3). The balance sheet is quite well-balanced, equal to $89.1 \%$ (Table 2) and reflects the distribution of the raw rainfall observed to the "net" rainfall, in the quantity of evapotranspired water and in the amount of water stored by the watershed.

The parameter $X$, which reflects the influence of an opening of the watershed to the outside, shows that for a value of $2.2>1$, the Wadi Bechar watershed looses the water either by evaporating to the atmosphere or by deeply

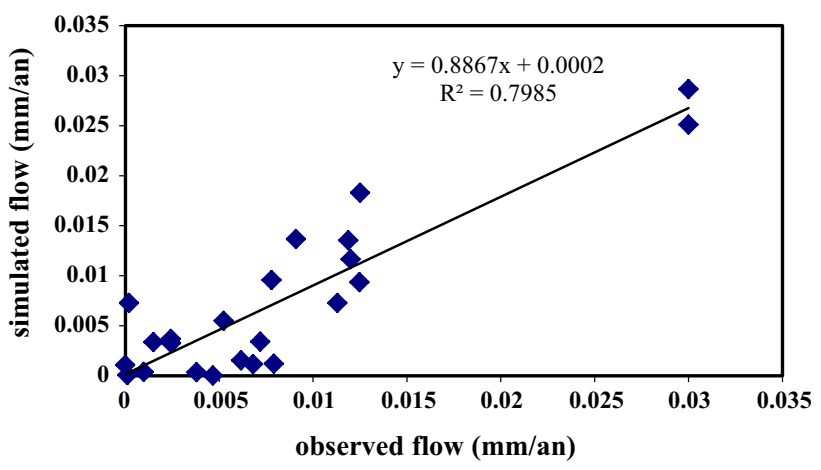

Fig. 4 Correlation between the observed flows and the simulated flows

infiltrating to the aquifers or to other adjacent watersheds of Wadi Zousfana and Wadi Guir. According to the values of the coefficients of determination, the calibration by the GR1A model is almost correct for the Wadi Bechar watershed. The Nash value (Table 2), after calibration, is rather good $(77.9 \%)$, with a correlation coefficient $R^{2}$ equal to 0.79 ; it is generally considered that this absolute value is greater than 0.70 , so there is a strong bond between the two series (Fig. 4); in the same climatic regime, Elhoussaoui et al. $(2015,2016)$ had found that $X=1, \mathrm{Nash}=85 \%$, $R^{2}=0.90$ in the studied watershed of Wadi Tamanrasset. These values illustrate a similarity between both the studied watersheds in the same climatic regime and are consistent with other results found by Bouanani et al. (2015) on the Tafna watershed in Algeria.
Fig. 3 Visualization of the calibration quality

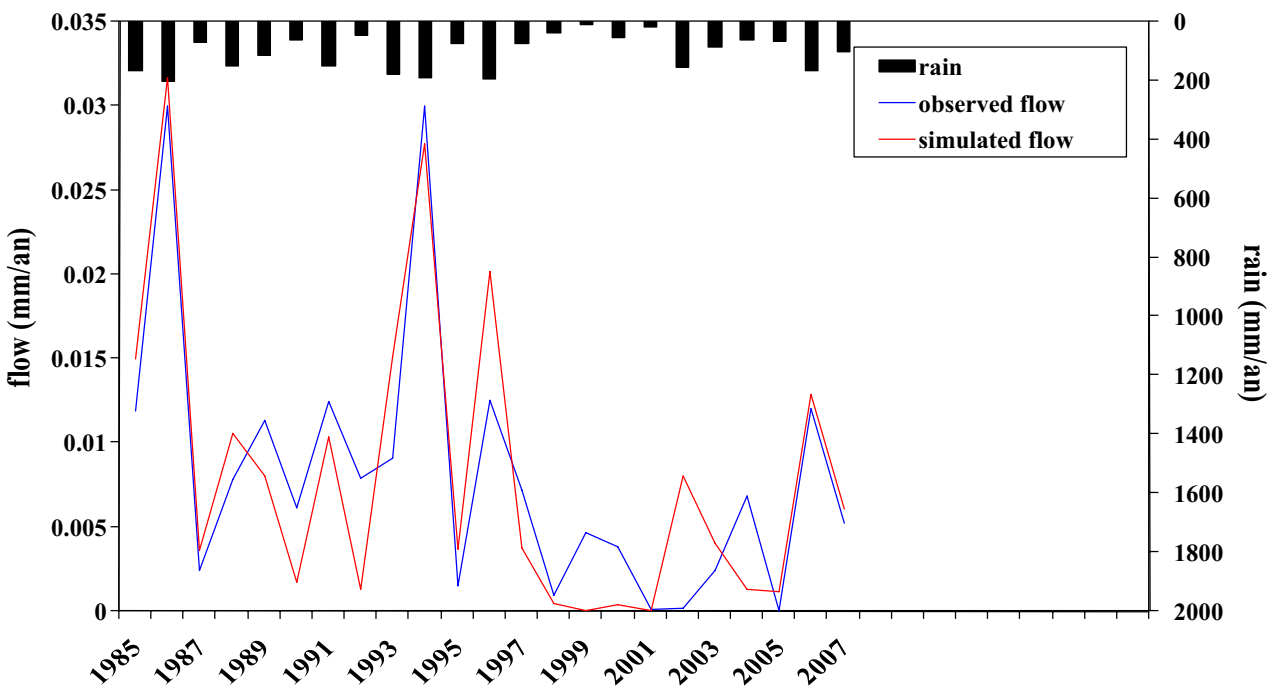


Table 3 Values of the parameters after calibration and performances of the Wadi Bechar watershed

\begin{tabular}{lllllll}
\hline Annual data & \multicolumn{2}{l}{ ETP (Turc) } \\
\cline { 2 - 7 } Criteria & $X 1$ & $X 2$ & Nash (\%) & Balance (\%) & $R_{0}$ & $R^{2}$ \\
\hline Wadi Bechar & 4.74 & 0.02 & 77.9 & 98.6 & 10 & 0.76 \\
\hline
\end{tabular}

$X 1$ Production tank capacity $(\mathrm{mm}), X 2$ exchange parameter $(\mathrm{mm})$

$R_{0}$ Initial fill level (max $=60 \mathrm{~mm}$ ), $R^{2}$ correlation coefficient, $R$ level of the routing tank

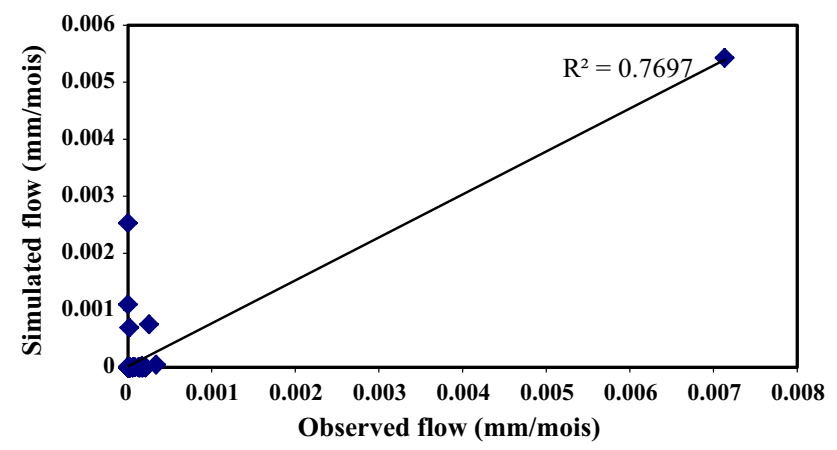

Fig. 5 Correlation between observed flows and simulated flows

\section{Monthly model GR2M}

We applied the GR2M model with the previously selected parameters on the whole series to simulate the flows of the average monthly ETP for the period 1999-2009 from the mean monthly rainfall observed.

We have carried out the changes in the values of the parameters $X 1$ and $X 2$ of the model, between the limit values between 110 and $2640 \mathrm{~mm}$ until obtaining the optimum values of the coefficients of determination, and the Nash criterion. The results of the calibration, coefficient of determination, and Nash criterion are presented in Table 3.

The calibration of the GR2M model was relatively more difficult compared to GR1A. It is a question of choosing the set of parameters $X 1$ and $X 2$ that best represents the operation of the watershed. We observe a good superposition of the hydrographs of the observed and calculated flows but sometimes with errors of amplitude.

The value of the Nash criterion in calibration is generally good for the Wadi Bechar watershed because it is equal 77.9 (Table 3). The curve of the water runoff calculated and the one measured indicates almost perfect overlaps for the Wadi Bechar watershed.

The rest is fairly balanced and is equal to $98.6 \%$ (Table 3). This balance reflects the distribution of the raw rainfall observed in "net" rainfall, in the amount of evapotranspired water and in the amount of water stored by the watershed. According to the values of the determination coefficients $X 1$ and $X 2$ (Table 3), the calibration for the monthly GR2M model seems correct.

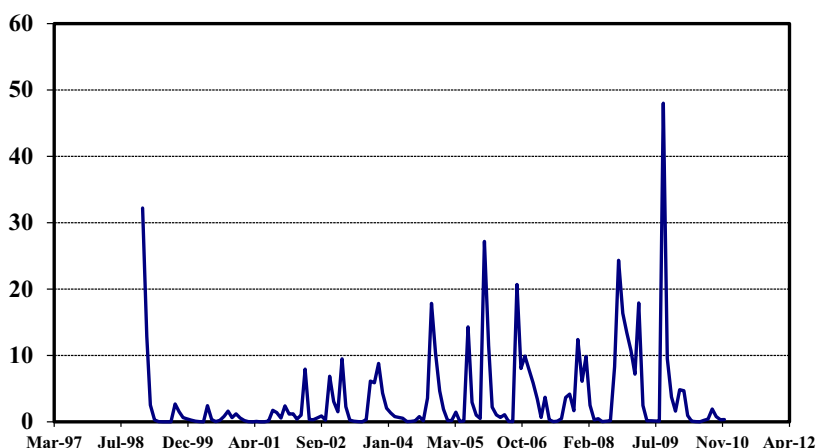

Fig. 6 Curve indicating the level $S$ of the production reservoir

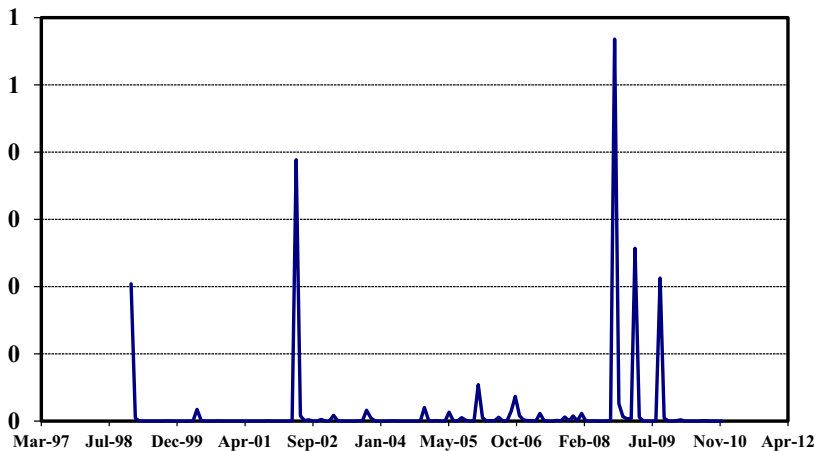

Fig. 7 Curve indicating the level $R$ of the routing tank

The value of the Nash criterion in calibration is generally good for the watershed of the Wadi Bechar, with a correlation coefficient $R^{2}$ equal to 0.76 ; it is considered optimal to have the value above 0.70 , (Fig. 5); in the same climatic regime, Elhoussaoui et al. $(2015,2016)$ had observed $X 1=76.73, X 2=0.66$, Nash $=70.1$, and $R^{2}=0.82$ in the studied watershed of Wadi Tamanrasset; these values illustrate a similarity between both the studied watersheds in the same climatic regime, and it is consistent with other results found by Bouanani et al. (2015) on the Tafna watershed in Algeria.

The value of the capacity parameter of the estimated production tank $X 1$ is $4.74 \mathrm{~mm}$, which reflects the production function, indicating the rainfall capacity transformed 
into available runoff at the scale of the Wadi Bechar watershed (Fig. 6).

The value of the estimated underground exchange coefficient parameter $X 1$ is equal to 0.02 , which translates the transfer function and indicates the movement of this runoff accumulated on the ground during precipitation to the outlet of the Wadi Bechar watershed (Fig. 7).

\section{Conclusion}

After this study focused on hydrological modeling, we can conclude that the two different annual and monthly timesteps (GR1A and GR2M) allowed us to evaluate the parameters of Nash and $R^{2}$ by using as input precipitation and evapotranspiration (ETP) data calculated by Turc's method and using the water runoff as output data. This work provides an answer to the questions posed in the initial sections and validate data whether on an annual or monthly scale in arid zones, which subsequently enabled us to supplement and extend our series of monthly and annual flows of the Wadi Bechar watershed. After an observation of the geographical location of the basin study in areas with arid climate, the rainfall was found to be low, which gives flows heterogeneous in time and space (irregularity). Flooding is rare but aggravating; analysis of the rainfall-runoff relationship shows that the Bechar station poses a slight anomaly for the monthly model GR2M due to the concentration time or due to significant infiltration resulting from the geographical formations, which requires a survey and study into the area. It is likely that rising temperatures in arid zones will intensify the hydrological cycle, resulting in greater flows in the downstream of the watershed.

Open Access This article is distributed under the terms of the Creative Commons Attribution 4.0 International License (http://creativeco mmons.org/licenses/by/4.0/), which permits unrestricted use, distribution, and reproduction in any medium, provided you give appropriate credit to the original author(s) and the source, provide a link to the Creative Commons license, and indicate if changes were made.

\section{References}

ANRH (National Agency for Hydraulic Resources) (2014) Global report on the South West region. unpublished report, Bechar Algeria

Bekhira A, Nebou M, Merzougi T (2014) Flood management in the Wadi Bechar watershed: hydrological study and development. Dissertation of master, University of Bechar Algeria

Bodian A, Alain D, Dacosta H (2012) Contribution of rainfall-runoff modeling to the knowledge of water resources: application to Upper Senegal River basin. J Climatol. https://doi.org/10.4267/climatolog ie. 223

Bodian A, Dezetter A, Dacosta H (2015) Rainfall-runoff modeling of water resources in the upper Senegal River basin. Int J Water Resour Dev. https://doi.org/10.1080/07900627.205.1026435
Bouanani R, Baba-Hamed K, Bouanani A (2015) Rainfall-runoff modeling by a global approach: case of the basin of the upper Tafna in Benibahdel NW Algeria. Sci Tech J, LJEE N 14(26):32-48

Deleau (1952) The region of Colomb-Bechar, printing house the Typolitho and J. Carbonel, Algeria

Elhoussaoui A, Baba-Hamed K, Bouanani R (2015) Hydrology and modeling of the rainfall-runoff function: case of the Wadi Tamanrasset watershed South-Algeria. Dissertation of master, University of Tlemcen

Elhoussaoui A, Baba-Hamed K, Bouanani A, Amours K (2016) Hydrology and rainfall-runoff modeling: case of Tamanrasset Wadi watershed South-Algeria. In: 2nd international conference on water resources (ICWR)

Hughes DA (2009) Monthly rainfall-runoff models applied to arid and semiarid catchments for water resource estimation purposes. Hydrol Sci J. https://doi.org/10.1080/02626669509491463

Kabouya M (1990) Rainfall-runoff modeling at monthly and annual time steps in northern Algeria. Doctoral dissertation, University of Paris South Orsay

Kabouya M, Michel C (1991) Estimation of surface water resources at monthly and annual time steps, application to a semi-arid country. J Water Sci. https://doi.org/10.7202/705116ar

Kouakou KE, Kouassi AM, Kouadio ZA, Goula BTA, Savane I (2016) Modeling hydrological watershed of Comoe in climate change context. Int J Innov Appl Stud 15:799

Lyon SW, King K, Polpanich OU, Lacombe G (2017) Assessing hydrologic changes across the Lower Mekong Basin. J Hydrol Reg Stud. https://doi.org/10.1016/j.ejrh.2017.06.007

Makhlouf Z, Michel C (1994) A two-parameter monthly water balance model for French watersheds. J Hydrol. https://doi. org/10.1016/0022-1694(94)90233-X

Mekideche D, Sai N, Touat S, Younsi N (1995) Hydrogeological map of the region of Bechar, explanatory note. National Agency for Hydraulic Resources, pp 27-39

Menchikoff N (1936) Geological study on the Algerian-Moroccan borders of the South. Bulletin of the Geological Society of France

Mouelhi S (2003) Towards a coherent chain of global conceptual rainfallrunoff models at annual, monthly and daily time steps. Doctoral dissertation, ENGREF, Cemagref Antony, France

Mouelhi S, Michel C, Perrin C, Andreassian V (2006) Linking stream flow to rainfall at the annual time step: the Manabe bucket model revisited. J Hydrol. https://doi.org/10.1016/j.jhydrol.2005.12.022

Mouelhi S, Madani K, Lebdi F (2013) A structural overview through GR(s) models characteristics for better yearly runoff simulation. Open J Mod Hydrol. https://doi.org/10.4236/ojmh.2013.34022

Nash JE, Sutcliffe JV (1970) River flow forecasting through conceptual models. Part I-a discussion of principles. J Hydrol. https://doi. org/10.1016/0022-1694(70)90255-6

Niemi TJ, Warsta L, Taka M, Hickman B, Pulkkinen S, Krebs G, Moisseev DN, Koivusalo H, Kokkonen T (2017) Applicability of open rainfall data to event-scale urban rainfall-runoff modeling. J Hydrol. https://doi.org/10.1016/j.jhydrol.2017.01.056

Nounangnonhou TC, Fifatin FXN, Aza-Gnandji RM, Acakpovi A, Sanya EA (2018) Forecast of impacts of climate change on hydropower potential of Ouémériver at the 2040's horizon in Benin. Int J Energy Power Eng. https://doi.org/10.11648/j.ijepe.20180701.12

Otmane A, Baba-Hamed K, Bouanani A, Safa A (2017) Predetermination of extreme flood values and the contribution of the SidiBelAbbès plain to the water balance of the oued Mekerra watershed. Revue des Techniques Sciences Méthodes. https://doi.org/10.1051/ tsm/201778027

Pareyn C (1961) The carboniferous massive of the South Oran Sahara (2 vols). Scientific Research National Center, France

Pilgrim DH, Chapman TG, Doran DG (2009) Problems of rainfall-runoff modeling in arid and semiarid regions. Hydrol Sci J. https://doi. org/10.1080/02626668809491261

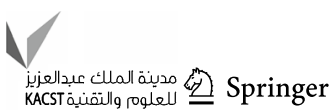


Rwasoka DT, Madamombe CE, Gumindoga W, Kabobah AT (2013) Calibration, validation, parameter indentifiability and uncertainty analysis of a 2-parameter parsimonious monthly rainfall-runoff model in two catchments in Zimbabwe. Phys Chem Earth. https:// doi.org/10.1016/j.pce.2013.09.015

Traore VB, Sambou S, Tamba S, Fall S, Diaw AT, Cisse MT (2014) Calibrating the rainfall-runoff model GR4J and GR2M onthe
Koulountou river basin, a tributary of the Gambia river. Am J Environ Prot. https://doi.org/10.11648/j.ajep.20140301.15

Publisher's Note Springer Nature remains neutral with regard to jurisdictional claims in published maps and institutional affiliations. 